\title{
GÊNERO FEMININO: IDENTIDADE E ESTEREÓTIPO - DILMA ROUSSEFF EM SEU PRIMEIRO MANDATO
}

\section{FEMININE GENDER: IDENTITY AND STEREOTYPE - DILMA ROUSEFF IN HER FIRST MANDATE}

Dina Maria Martins Ferreira ${ }^{1 *}$

Dulce Valente Pereira ${ }^{2 * *}$

Universidade Estadual do Ceará

\section{RESUMO}

Neste artigo, buscamos analisar a identidade feminina em discursos de Dilma Rousseff, primeiro mandato, tendo em vista, de um lado, os estereótipos históricos da "feminilitude" que valorizam a falocracia, e, de outro, posições de "feminilitude" que valorizam a práxis do feminino, em posição feminista. Para tal, são levantados sentidos linguístico-discursivos com vistas não somente à reprodução de estereótipos históricos, mas também à contestação e ressignificação destes. Nossa análise linguísticodiscursiva prioriza macro-categorias: ethos discursivo, feminilidade e "feminilitude", cujo propósito é identificar os performativos identitários da "feminilitude", tais como legitimação e resistência frente a uma ordem social histórica falocrática. E diante desta trincheira, um ethos discursivo se configura por micro-categorias: ruptura, identificação, agenciamento, empoderamento e contestação. Mesmo diante deste quadro teóricocategorial, que privilegia as trincheiras de resistência às ações históricotradicionais, ainda verifica-se a ordem social e as ações históricotradicionais do falocrático.

PALAVRAS-CHAVE: identidade; estereótipo; ethos; performatividade.

$1{ }^{*} 2^{\circ}$ pós-doutorado, em Estudos Sociais, pela Université Paris V, Sorbonne, em co-tutoria em Estudos da Linguagem, pela Unicamp/IEL (2009-2010); $1^{\circ}$ pós-doutorado, em Linguística e Pragmática pelo Instituto de Estudos da Linguagem/Unicamp (2002-2003); doutorado, em Linguística, pela UFRJ (1995); Docente e Pesquisadora do Programa de Pós-Graduação em Linguística Aplicada pela Universidade Estadual do Ceará e membro-pesquisador do Centre d' Études sur les Actuels et le Quotidien, Paris V, Sorbonne. Autora de 3 livros e organizadora de 5 livros, mais artigos em revistas nacionais e internacionais. E-mail: dinaferreira@terra.com.br

2 ** Mestre em Linguística Aplicada pelo Programa de Pós-Graduação em Linguística Aplicada, Universidade Estadual do Ceará (2013); doutoranda do referido programa, Universidade Estadual do Ceará. E-mail: dulcevalper@hotmail.com 


\begin{abstract}
In this article, we analyze the feminine identity in speeches of Dilma Rousseff, in her first mandate: on the one hand, the historical stereotypes of femininility under the phallocratic value, and on the other positions feminilitude who value women's praxis in feminist position. To do this, they are raised linguistic-discursive meanings with a view not only to the reproduction of historical stereotypes, but also to their defense and reframing. Our linguistic and discourse analysis gives priority to macrocategories: discursive ethos, femininility and feminilitude whose purpose is to construct the identity of the performative feminilitude such as legitimation and resistance against a historical social order phallocratic. And before this trench, a discursive ethos is shaped by micro-categories: rupture, identification, agency, empowerment and defense. Even before this theoretical and categorical framework which favors the trenches of resistance to the historical-traditional actions, yet there is a social and historical-traditional phallocratic actions.
\end{abstract}

KEYWORDS: identity; stereotype; ethos; performativity

\title{
INTRODUÇÃO
}

Segundo Bhabha (2010), as relações de gênero são fortemente marcadas por estereótipos, os quais, pela "força da ambivalência", têm sido reiterados ao longo dos mais diversos contextos de práxis humana. As propriedades que caracterizam o estereótipo, segundo este autor, são a sua capacidade de repetibilidade em conjunturas históricas e discursivas, estratégias de individuação e marginalização e os efeitos de verdade.

Dessa forma, o que motivou a investigação da identidade feminina no discurso da presidente Dilma Rousseff foi o fato dela ter sido alvo de inúmeros comentários, empreendidos pela imprensa nacional, que reiteravam estereótipos históricos de gênero, em relação à figura da mulher, os quais, ao produzirem efeitos de verdade, reiteravam o poder de discriminar. Em outros termos, Dilma, assim que assumiu o mais alto cargo de comando público e político do executivo brasileiro, foi alvo de processos de estereotipagem que diziam respeito a sua condição de mulher, e não a de política. E, por esta troca de posição, da função política para a de mulher, 
não estaria Dilma Rousseff ressignificando os estereótipos históricos masculinos de gênero? E também não estaria estilizando uma identidade : feminina de resistência frente à ordem social histórica falocrática?

Para responder a estas questões, este artigo se volta para uma perspectiva pragmático-discursiva em que uma rede teórico-analítica se constitui: categorias analíticas "feminilidade" e "feminilitude" (Martins Ferreira, 2009), - que diferenciam as performances do feminino -; ethos discursivo (Maingueneau, 2006; 2008); e estilização de três construtos identitários femininos - legitimação, resistência e projeto (Castells, 2010) em relação aos sentidos de uma "ordem social" masculina (Bourdieu, 2010). E, por fim, nesta rede, incluímos algumas considerações sobre o uso da linguagem que não só reivindica pelo ato de fala como também pelo movimento do corpo, ou seja, a "imagem do feminino" no discurso de Dilma se constituiu por seu "modo de dizer" articulado a seu movimento do corpo.

\section{Performatividade em linguagem}

Austin (1990) foi quem argumentou sobre a ideia de que a linguagem consiste numa ação semelhante a tantas outras ações, tais como correr, andar, comer, etc. Assim, o autor denominou de "ato performativo" ou simplesmente "performativo" - atos de fala que realizam uma ação, ao invés de descrevê-la. Em outros termos, ao traçar uma distinção entre dois diferentes tipos de atos de fala, a saber, o constativo e o performativo, distinção que mais adiante abandonará, ele argumentou que existem determinados acontecimentos que somente referendam performativos no uso da linguagem.

Judith Butler (2010. p. 59), teórica feminista, radicalizou o ato performativo austiniano e propôs a noção de "performatividade de gênero". Segundo ela, "o gênero é a estilização repetida do corpo, um conjunto de atos repetidos no interior de uma estrutura reguladora altamente rígida, a qual se cristaliza no tempo para produzir a aparência de uma substância, de uma classe natural do ser". Em outros termos, Pinto (2002, p. 83), pesquisadora brasileira a qual tem se debruçado sobre os estudos de gênero com foco sobre a relação linguagem-corpo, reutilizou o pensamento de Butler, expressando-o da seguinte forma: o "sujeito de fala é aquele que 
: produz um ato corporalmente; o ato de fala exige o corpo. $\mathrm{O}$ agir no ato de

: fala é o agir do corpo, e definir esse agir é justamente discutir a relação entre linguagem e corpo". Em suma, a ênfase estaria na relação entre fala e corpo, em cuja linguagem constitui-se a identidade de gênero.

Silva (2008) alia o pensamento de Austin ao de Butler, e propõe pressupostos teóricos a respeito da produção social da identidade e da diferença. Para o autor não basta "celebrar" as identidades e suas diferenças, mas também questionar sobre o modo como são produzidas e sobre as suas consequências políticas, ou seja, os construtos identitários são produzidos por atos de fala ilocucionários que projetam atos perlocucionais. Daí a razão de Silva (2008) argumentar que a identidade e a diferença, além de serem criações de atos de fala, são 'criaturas' do mundo social e cultural, não podendo ser naturalizadas, cristalizadas, essencializadas, na medida em que não pertencem ao mundo natural ou transcendental. De modo específico, diz o teórico, tanto a identidade quanto a diferença não são positividades, ou seja, não fazem referência a si mesmo, não são autocontidas, autodeterminadas, não são fixas nem estáveis, pois se assim o fossem, tal concepção pressuporia um sujeito estável, fixo, uno, centrado em si mesmo.

E nesta 'briga' entre instável e estável, Silva (2008) argumenta que o processo de produção da identidade oscila entre dois movimentos, a saber, entre processos que tendem a fixá-la e a estabilizá-la e processos que tendem a subvertê-la e a desestabilizá-la. Segundo o teórico, um modo pelo qual a identidade tem sido fixada se deve às interpretações biológicas que apelam para a natureza. Enquanto os essencialismos, diz ele, nascem do movimento de fixação da ordem da ontologia, a produção da identidade e da diferença se dá por meio de processos discursivos e linguísticos, porquanto sujeito e identidade, senão o gênero, são governados pela linguagem. Resta-nos saber em que concepção de linguagem ele está situado.

Segundo Derrida (1991), o significado não se fecha sobre si mesmo, e dada a insaturação dos contextos, estes são reiterados para além do instante de sua inscrição. Assim sendo, a linguagem não consiste numa estrutura que permanece a mesma - constante, contínua -, mas, sim, pela instabilidade. De acordo com este autor, o signo é caracterizado pelo diferimento ou adiamento, bem como pela diferença, pois a "presença" do referente (da "coisa" ou do "conceito") é algo que nunca se concretiza, é indefinidamente 
adiado. Consequentemente a impossibilidade da "presença" - metafísica da presença - obriga o signo a depender de um processo de diferenciação : - différance. O signo seria a um "traço" daquilo que ele não é, a saber, da diferença, bem como daquilo que ele substitui. Em suma, o signo tem sua existência marcada pela diferença, a qual sobrevive nele como "traço". E se os sujeitos são governados por "uma estrutura que balança”, pontua Silva (2008, p. 80), então tanto a identidade quanto a diferença são marcadas pela indeterminação.

Silva (2008, p. 94-95) abraça a compreensão de Derrida sobre a linguagem, para quem o signo é repetível, ou seja, propriedade da iterabilidade em linguagem - repetição em novo. Ou melhor, assume-se a retirada de linguagem de um determinado contexto para inserção em outros contextos diferentes, como uma operação de "recorte" e "colagem"; a saber, a retirada de uma expressão de um contexto social mais amplo em que ela foi tantas vezes enunciada e a (re) inscrição da mesma expressão em um novo contexto, no qual irá reaparecer sob o disfarce de uma operação mental exclusiva. Em suma, tal operação recoloca em ação o enunciado performativo, cuja repetibilidade estaria para a eficácia dos atos performativos.

\subsection{Performatividade de gênero}

Se a identidade é produzida por atos linguísticos, então o gênero também consiste numa criação feita pelos mesmos atos. E, retomando as perspectivas conceituais de Judith Butler (2010), na medida em que gênero é tratado como performatividade, fica claro a relação entre linguagem, discurso e gênero.

Primeiramente, julgamos importante registrar que para Butler (2010) não existe sujeito, nem tampouco identidade cuja constituição dos significados ocorra anteriormente a qualquer processo discursivo, ou melhor, não existiria um 'status ontológico' por trás do gênero, pois a sua constituição se dá 'na' e 'através' da linguagem. A proposta desta autora sobre a teoria do gênero se apoia tanto no pensamento de Austin (1990), quanto no de Derrida (1991), contrariando os pressupostos da metafísica ocidental, os quais, segundo Derrida, rebaixou a "escritura" a uma função designativa, reveladora de sentidos produzidos fora das relações sociais 
reais e do mundo social. Em síntese, os novos estudos sobre a relação entre : linguagem, discurso e gênero, não nos termos da referida tradição filosófica de pensamento ocidental, adquire importância, principalmente, para o questionamento das relações assimétricas de poder entre os gêneros, pois, assim sendo, em termos "performativos", podemos contestar, seguindo os passos de Austin, Derrida e de Butler, as possíveis hierarquias originadas pelas/nas dicotomias, que têm alicerçado, ao longo dos tempos, as relações entre homens e mulheres.

No que tange ao gênero, Butler (2010) persegue pontos problemáticos tanto da teoria quanto da política feminista, contesta discursos os quais concebem como da "ordem da natureza" a questão de gênero, ou seja, da sexualidade, do desejo, do sexo, do ato sexual, como algo os quais não podem, segundo uma matriz cultural heteronormativa compulsória, fugir à "normatividade". Com foco sobre a homossexualidade, a autora argumenta sobre a existência de matrizes culturais subversivas que eclodem do interior da própria matriz normativa, ou seja, gêneros culturais ininteligíveis subvertem e deslocam a matriz normativa do seu próprio interior. Especificamente, em referência à questão do corpo, algo que adquire relevância em sua teoria, questiona o tratamento, recebido tanto pelo pensamento cristão quanto pelo cartesiano, como um "meio passivo":

A distinção sexo/ gênero e a própria categoria sexual parecem pressupor por uma generalização do "corpo" que preexiste à aquisição de seu significado sexuado. Amiúde, esse "corpo" parece ser um meio passivo, que é significado por uma inscrição a partir de uma fonte cultural representada como "externa" em relação a ele. Contudo, quando o "corpo" é apresentado como passivo e anterior ao discurso, qualquer teoria do corpo culturalmente construido tem a obrigação de questioná-lo como um construto cuja generalidade é suspeita. Essas concepções têm precedentes cristãos e cartesianos, os quais, antes do surgimento da biologia vitalista no século XIX, compreendiam o "corpo" como matéria inerte que nada significa [...] (Butler, 2010, p. 185-186) (grifo nosso). 
A autora reforça sua contrariedade em relação à acepção de passividade dada ao corpo:

O fato de o corpo gênero ser marcado pelo o performativo [e] sugere que ele não tem status ontológico separado dos vários que constituem sua realidade. Isso também sugere que, se a realidade é fabricada como uma essência interna, essa própria interioridade é efeito e função de um discurso decididamente social e público, da regulação pública da fantasia pela política da superfície do corpo, do controle da fronteira do gênero que diferencia interno e externo e, assim, institui a "integridade" do sujeito. Em outras palavras, os atos e gestos, os desejos articulados e postos em ato criam a ilusão de um núcleo interno e organizador do gênero, ilusão mantida discursivamente com o proposito de regular a sexualidade nos termos da estrutura obrigatória da heterossexualidade reprodutora (Butler,2010, p. 194-195) (grifo nosso).

Dessa forma, podemos observar que confluem para a noção de performatividade tanto a fala quanto o corpo. E é por "palavras, atos e gestos" que ocorre a constituição do sujeito, ou melhor, de sua identidade de gênero.

\section{Estereótipo}

Para Amossy (2008, p. 125), o estereótipo é uma noção partícipe do estabelecimento do ethos. O processo de estereotipagem, segundo a autora, consiste num "esquema coletivo cristalizado", ou, dito de outro modo, numa "representação cultural preexistente". Antes mesmo que ocorra a interação entre locutor e destinatário, ambos já se valem de tais esquemas, antecipando imagens um do outro - esquema coletivo e representação cultural. Para que tais imagens sejam reconhecidas é preciso, esclarece a autora, que estejam assumidas em uma "doxa", ou seja, que estejam relacionadas a "modelos culturais pregnantes".

Amossy (2008, p. 126) ainda nos informa sobre o modo como algumas perspectivas concebem o estereótipo, por exemplo, enquanto que para as práticas sociológicas e as semiológicas tal noção se refere a uma 
: constante de predicados, para a perspectiva argumentativa o referido termo : tem a função de designar tanto os "modos de raciocínio" específicos de um grupo quanto os "conteúdos globais do setor da doxa", na qual o orador se encontra situado. Estereótipo, então, seria

o conjunto das características que se relacionam à pessoa do orador e à situação na qual esses traços se manifestam que permitem construir sua imagem. Se esta é sempre em última instância singular, é preciso ver, entretanto, que a reconstrução se efetua com a ajuda de modelos culturais que facilitam a integração dos dados em um esquema preexistente (Amossy, 2008, p. 127) (grifo nosso).

Em suma, ao que parece, a estereotipagem consiste num processo de reconstrução de dados preexistentes e integrados a um modelo cultural, o qual, por sua vez, dá a forma ao estereótipo de um "esquema" ou "representação" partilhada por uma comunidade, grupo, numa dada situação.

Contudo, Bhabha (2010) oferece uma concepção de estereótipo mais produtiva, pois mesmo que confira certa estabilidade de significações, as mesmas podem ser ressignificadas. Dessa forma, diz ele, estereótipo se caracteriza como uma estratégia discursiva ambivalente, ou seja, paradoxal, pois tanto reivindica a fixação quanto o movimento. A ambivalência é quem valida as propriedades do estereótipo, a saber, a repetibilidade em conjunturas históricas e discursivas, os efeitos de verdade que carrega e as estratégias de individuação e marginalização que opera. Em suma, o autor argumenta que o estereótipo se trata de uma crença dividida e múltipla, que reivindica uma cadeia contínua e repetitiva de outros estereótipos.

De modo específico, Bhabha (2010, p. 116) concebe o estereótipo como "fetiche", pois o mesmo se trata de um "jogo" entre "afirmações de totalidade/similaridade" e a "ansiedade associada com a falta e a diferença". Em outros termos, "O estereótipo é um modo de representação complexo, ambivalente e contraditório, ansioso na mesma proporção em que é afirmativo" (p.110). O referido "jogo" se dá entre as seguintes posições: metafóricas/narcísicas e metonímicas/agressivas, cujos funcionamentos ocorrem de modo simultâneo e estratégico, pois são colocadas em relação 
umas às outras. Enquanto a metáfora diz respeito ao mascaramento da ausência e da diferença, a metonímia desempenha a função de registrar a falta percebida. Por sua vez, as formas de identificação narcísica e agressiva dizem respeito, respectivamente, a dominação e ao prazer e a ansiedade e a defesa. Em suma, é o estereótipo ou fetiche que possibilita uma identidade baseada nas posições anteriormente citadas:

Há uma amarração entre a função metafórica ou mascaradora do fetiche e o objeto-escolha narcísico e uma aliança oposta entre a figuração metonímica da falta e a fase agressiva do imaginário. Um repertório de posições conflituosas constitui o sujeito [...]. A tomada de qualquer posição, dentro de uma forma discursiva especifica, em uma conjuntura histórica particular, é portanto sempre problemática - lugar tanto da fixidez como da fantasia (Bhabha, 2010, p. 119-120) (grifo nosso).

Como podemos observar a concepção de estereótipo, segundo Bhabha (2010), diferentemente de Amossy (2008), põe em destaque o conflito, a contradição, ou seja, o estereótipo não é simplesmente um "dado" fechado o qual é possível ser reconstruído por meio de um esquema cultural partilhado ou uma série de predicados para serem descritos, mas algo ansioso, um objeto "impossível” (Bhabha, 2010, p. 125). Mas, o que julgamos importante reter do pensamento do referido autor é o fato dele contestar o estereótipo como um "ponto seguro de identificação" (p. 110) e trazer à tona a questão do poder que estabelece assimetrias entre os sujeitos.

\section{Ethos discursivo: feminilidade e 'feminilitude'}

Enquanto que, para Butler (2010, p.59), a performance consiste na "estilização repetida do corpo", para Derrida (1991), a performance se dá por meio da "iterabilidade" da linguagem, para Silva (2008), se trata de uma operação de "recorte" e "colagem", e, para Bhabha (2010), uma questão de ambivalência, podemos aventar, pelos ditos anteriores, que a identidade, e consequentemente o estereótipo, vacilam entre o que está no lugar temporariamente e a ansiedade por uma "presença" que nunca irá se concretizar, ou seja, entre aqueles sentidos que são fixados e subvertidos num só lance. 
E, deste ponto em diante, abre-se uma discussão sobre a noção de : ethos, a qual consiste em algo bastante antigo, se nos remetermos à Retórica de Aristóteles (2005). Segundo Maingueneau (2006), o ethos aristotélico dizia respeito à boa impressão que o orador deveria causar no auditório, através do modo como o mesmo constituía o seu discurso. $\mathrm{O}$ orador deveria mobilizar por meio da sua fala três qualidades fundamentais: a prudência, a virtude e a benevolência. Vale ressaltar que tais qualidades eram, para o destinatário, características "intradiscursivas", portanto, o que julgamos importante reter sobre a concepção aristotélica de ethos é que não eram levados em conta o saber extradiscursivo. Assim, ao que parece, tais características "intradiscursivas" que emergiam durante a enunciação eram algo concebidas como "dadas", as quais eram reveladas 'na' e 'pela' fala do orador.

Contudo, para além do ethos retórico, Maingueneau (2006, p. 268) argumenta que as características que fluem por meio do modo como o orador constrói o seu discurso não consistem em algo "estritamente intradiscursivas", pois "na elaboração do ethos intervêm igualmente dados exteriores à fala propriamente dita (gestos, roupas, ...)":

Ora, a noção de ethos permite articular corpo e discurso: a instância subjetiva que se manifesta através do discurso não se deixa perceber neste apenas como um estatuto, mas sim como uma voz associada à representação de um "corpo enunciante" historicamente especificado (Maingueneau, 2006, p. 271).

Ao afirmar sobre a existência de dados exteriores, Maingueneau (2006) considera problemático na Retórica a não consideração às possíveis representações que os destinatários possam ter do orador, mesmo antes de sua fala. Contudo, o autor não se distancia por completo das premissas aristotélicas, já que afirma que (1) o ethos é "uma noção discursiva; que está (2) "intrinsecamente ligado a um processo interativo de influência sobre o outro"; e que o mesmo consiste em (3) "uma noção intrinsecamente híbrida", ou seja, sociodiscursiva. Nestes termos, a noção de ethos, diz o teórico, permite refletirmos sobre o que conduz os sujeitos a aderirem a um dado ponto de vista advogado por um dado discurso. Tal adesão diz respeito 
ao modo como os intérpretes se apropriam do ethos de quem discursa, e tal apropriação, por sua vez, é designada pelo termo "incorporação":

O ethos constitui, assim, um articulador de grande polivalência. Recusa toda separação entre o texto e o corpo, mas também entre o mundo representado e a enunciação que o traz: a qualidade do ethos remete a um fiador que, através desse ethos, proporciona a si mesmo uma identidade em correlação direta com o mundo que lhe cabe fazer surgir. (Maingueneau, 2006, p. 278) (grifo nosso).

Portanto, diferentemente do ethos aristotélico, Maingueneau (2006) reformula tal noção ao incluir o extradiscursivo como, por exemplo, o corpo na constituição da imagem de si pelo discurso, ou seja, o ethos vai além de uma simples estratégia. Segundo Fiorin (2012, p. 70), as teorias do discurso apontam para a existência de três elementos configuradores de um ethos: características físicas, psicológicas e tom de voz. Isto posto, características como, por exemplo, a prudência, consistem no resultado da articulação da fala e do movimento do corpo de quem discursa, numa situação de comunicação específica a qual está historicamente situada.

Ressaltamos que o ethos foi mobilizado pela ideia de performatividade, pois intuímos identificar as características físicas, psicológicas e tom de vOz tanto da "feminilidade" quanto da "feminilitude" (Martins Ferreira, 2009) ambas dizem respeito ao feminino, respectivamente, aos sentidos tradicionais que caracterizam a mulher pela maternidade, lar, doçura, delicadeza, emoção, etc., e, aos sentidos que caracterizam a mulher moderna, inserida na força produtiva do trabalho, escolarizada, determinada, independente, objetiva, racional, etc. De modo específico, esta autora justifica a manutenção dessa "teia identitária do feminino" (Martins Ferreira, 2009, p. 144) pelas seguintes razões:

Primeiro, porque a feminilidade atende a significações constitutivas de valorações patriarcais ainda existentes em nossa sociedade. Discordando ou não se o perfil da mulher feminilidade está em extinção devido à força de trabalho feminino, ainda este flanco da feminidade faz parte do imaginário popular, haja vista a ainda proliferação midiática 
de uma imagem feminina idealizada: mulher princesinha, protegida dos percalços da vida, esposa, mãe, companheira no mundo masculino, bonita, elegante, jovem, senhora, distinta, disponível às solicitações do grupo familiar. Segundo, porque a "feminilitude" daria sustentação à pratica social da mulher política: a mulher agente, diretora de seu caminho.

Em suma, Martins Ferreira (2009, p. 154) esclarece que tais sentidos são solidários e, que uma "classificação fronteirizada" não se sustenta, por ser um objeto impossível.

\section{Construção da identidade feminina}

Por meio da articulação das categorias analíticas "ethos", "feminilidade" e "feminilitude", buscamos identificar a performance social de três diferentes tipos de identidade feminina frente aos sentidos de uma "ordem social" histórica masculina, são elas: a "identidade de legitimação", a "identidade de resistência" e a "identidade de "projeto".

Castells (2010, p. 24) define diferentes tipos de identidade: a primeira diz respeito às instituições dominantes que a introduzem com o objetivo de mobilizar, expandindo e racionalizando a sua dominação; a segunda diz respeito aos atores sociais que se encontram nas trincheiras de resistência, ou seja, diferentemente da primeira, tal identidade é criada pelos sujeitos que se encontram no interstícios, cujas condições ou posições tanto são desvalorizadas quanto estigmatizadas, e cujos princípios diferem daqueles que constituem as instituições dominantes da sociedade; a terceira, por sua vez, refere-se à construção de uma nova identidade pelos atores sociais por meio da mobilização do material cultural que possam ter ao seu alcance, cujas consequências poderão ser a redefinição da posição social dos mesmos e a transformação de toda a estrutura social.

Vale ressaltar ainda que, segundo Castells (2010, p.17-18), tais identidades, dentre tantos fatores, resultam das tendências conflitantes da globalização as quais têm moldado tanto o mundo quanto a vida dos sujeitos. Em suma, o sociólogo argumenta que "vivenciamos no último quarto do século o avanço de expressões poderosas de identidade coletiva" as quais 
têm desafiado o projeto da globalização, pois "essas expressões encerram acepções múltiplas, são altamente diversificadas e seguem os contornos pertinentes a cada cultura, bem como às fontes históricas da formação de cada identidade". Acrescenta-se a isso, o fato que "a construção social da identidade sempre ocorre em um contexto marcado por relações de poder" (Castells, 2010, p.24).

Em meio a essa discussão, inserimos, para relacionar à questão do feminino, especificamente, à questão da identidade, as reflexões de Bourdieu (2010, p.100) que argumenta sobre a existência de uma "ordem social" masculina, na qual a mulher é concebida pela "arte" de se fazer "pequena". Segundo o autor, a referida ordem tem sido reproduzida ao longo dos tempos por conta de um trabalho histórico de "(re) criação das estruturas objetivas e subjetivas da dominação masculina”, garantido, até então, por três diferentes tipos de instituições: a Família, a Igreja e a Escola, as quais por meio de seus agentes e mecanismos têm agido sobre as estruturas inconscientes dos sujeitos. É o princípio falo-narcísico representado de modo paradigmático por estruturas que se encontram em estado fragmentado tanto nas estruturas cognitivas quanto nas sociais. No entanto, diz este autor, as transformações que ocorreram das estruturas produtivas, - que inclui o desenvolvimento das administrações públicas e privadas -, por conta do acesso de mulheres ao ensino, principalmente, superior, foi uma importante mudança que marcou as relações de gênero, pois promoveu desestabilizações na estrutura da dominação masculina, cujos efeitos, devido ao "aumento do acesso das mulheres à instrução", desenvolveram uma maior "independência econômica" e cofiguraram uma “transformação das estruturas familiares” (Bourdieu, 2010, p. 107).

\subsection{Dilma Rousseff: perspectivas analíticas}

Para demonstrar as categorias analíticas até então discorridas, elegemos o discurso da Presidenta da República, Dilma Rousseff, durante Colóquio de Alto Nível sobre Participação Política de Mulheres, ocorrido no dia 19 de setembro de 2011, em Nova York/EUA33, na medida em que reforça a figura feminina na política e, consequentemente, a performatividade de gênero.

3 Disponível em: < http://www2.planalto.gov.br> Último acesso em: 18 out. 2015. 
Alguns fragmentos são eleitos para análise:

(1) Depois de amanhã serei a primeira mulher, na história das Nações Unidas, a abrir os debates da Assembleia Geral. Gostaria de compartilhar essa honra com todas as mulheres aqui presentes, em especial com a subsecretária Michelle Bachelet, a primeira mulher da América do Sul a ser eleita Presidenta do seu país [...].

Dilma Rousseff não esconde seu contentamento ao presidir a abertura dessa Assembleia, num lugar predominantemente masculino. Ela deixa bem claro essa predominância, quando diz "serei a primeira mulher". Assim, podemos observar a performance de sentidos linguístico-discursivos da "feminilitude", a saber, de orgulho e de entusiasmo, pois a mesma se apresenta como uma mulher que irá promover uma mudança no cenário político internacional, - não muito diferente de tantos outros cenários políticos nacionais/locais, nos quais ainda predominam a figura masculina. Em suma, podemos observar a força da historicidade da "dominação masculina" sendo deslocada. Portanto, as características estilizadas no e pelo discurso da referida mulher no cenário político configuram um ethos de "ruptura" com aquelas significações naturalizadas que constituem uma "ordem social" falocrática objetiva no mundo social como, por exemplo, na referida assembleia;

(2) Apesar de alguns avanços notáveis, a desigualdade permanece. Em pleno século XXI, são as mulheres as que mais sofrem com a pobreza extrema, o analfabetismo, as falhas dos sistemas de Saúde, os conflitos e a violência sexual. Em geral, as mulheres ainda recebem salários menores pela mesma atividade profissional e têm presença reduzida nas principais instâncias decisórias [...].

No trecho acima, Dilma contesta. De modo específico, os sentidos performativizados são os de "contestação" e os de "indignação" entrelaçados aos de "descontentamento". De modo especifico, os sentidos linguísticodiscursivos que estão sendo reiterados em seu discurso constituem uma imagem do feminino que diz respeito à "feminilitude", pois a presidenta ${ }^{4}$

4 É do conhecimento do senso comum que Dilma Rousseff faz questão de ser chamada por "presidenta" em vez de "presidente", mesmo em detrimento da gramática normativa, como forma de salientar a performatividade do gênero feminino. 
se mostra uma mulher ciente das muitas demandas sociais que devem ser atendidas, ou seja, da transformação desse quadro problemático para que : não se perpetue mais. Podemos observar a estilização da "contestação" no instante em que ela traz à tona o paradoxo entre o momento histórico atual, a saber, século XXI, e a situação social fragilizada, portanto, problemática em que muitas mulheres ainda se encontram pela expressão "menores salários" e "presença reduzida nas principais instâncias decisórias", fatos que colaboram com a permanência das relações assimetrias de poder entre os gêneros. Acrescenta-se a esses fatores efeitos de sentidos de "indignação" no discurso de Rousseff, pelo fato de a mulher ser reduzida à condição de objeto, segundo um mercado de bens simbólicos, no momento em que aponta para a ocorrência da "violência sexual". Essas características configuram um ethos de "contestação";

(3) A crise econômica e as respostas equivocadas a ela podem agravar esse cenário, intensificando a feminização da pobreza. Por isso, combater as consequências e também as causas da crise é essencial para o empoderamento das mulheres [...].

Aqui, podemos observar uma construção discursiva de sentidos da "feminilitude", pois, em meio à época da crise econômica que solapava a Europa, Dilma reage aos equívocos gerados por decisões políticas, econômicas, sociais, etc., as quais, ao invés de contribuírem para uma mudança da condição social feminina, deveriam, antes, indagar se não estariam promovendo retrocessos. Contextualizando a crise, segundo os noticiários, uma das primeiras medidas consistiu em demissões em massa, ou seja, um grande número de trabalhadores perderam seus empregos. A nosso ver, uma das instâncias a serem atingidas fatalmente por essa crise foi a família. E a mulher, em consideração a forte ligação que a mesma tem com o universo doméstico tanto em estado objetivado quanto subjetivado, segundo um contexto de dominação masculina, talvez estivesse sendo ou poderia ser a primeira da lista desses cortes. Consequentemente, aos homens estaria sendo reservado o direito de permanecerem em seus empregos. Caso a questão tenha se encaminhado nos referidos termos, ao que parece, Rousseff estaria colocando em relevo o fato de as possíveis demissões de mulheres não estarem ocorrendo segundo uma visão masculina/ falocrática. 
: Dessa forma, podemos observar a configuração no discurso de Dilma de : um ethos de "contestação";

(4) Fui eleita a primeira mulher Presidenta do Brasil 121 anos depois da Proclamação da República e 78 anos depois da conquista do voto feminino. Somos $52 \%$ dos eleitores, mas apenas $10 \%$ do Congresso Nacional. Tenho me esforçado para ampliar a contribuição feminina nos espaços decisórios - dez Ministérios do meu governo são comandados por mulheres. Em especial, quero enfatizar que o núcleo central do meu governo é constituído por mulheres ministras $[\ldots]$.

Dois contextos históricos são trazidos à tona na fala de Dilma: um diz respeito ao período de transição da monarquia para a república, o outro se refere à conquista das mulheres ao direito de participação nas decisões políticas do Brasil. Podemos observar a performance de sentidos linguístico-discursivos tanto de "preocupação" com o atual cenário político, ou seja, com a disparidade entre os " $52 \%$ dos eleitores" serem mulheres e somente " $10 \%$ " delas integrarem os espaços públicos de poder, quanto de "esforço", para ressignificar tal realidade, pois já se passaram "78 anos depois da conquista do voto feminino" e os resultados de participação política das mulheres nas instâncias do legislativo e do executivo são ainda insignificantes. Os sentidos linguageiros são os da "feminilitude", ou seja, a imagem de si do feminino estilizada em seu discurso apontam para uma mulher que reivindica, combatente. Concluímos que tais características constituem um ethos de "identificação", um ethos de "agenciamento", bem como um ethos de "empoderamento";

(5) Comecei meu governo lançando um novo desafio: erradicar a pobreza extrema. São as próprias mulheres, que tanto sofrem com a pobreza, as principais aliadas das políticas voltadas para a sua superação. Elas têm prioridade em programas sociais, como o de transferência de renda e o de crédito para habitação, o que se reverte na melhoria da qualidade de vida delas mesmas e de suas famílias. São elas que, na família, se encarregam de gerir os benefícios originários das nossas políticas sociais [...]. 
No trecho acima, os sentidos linguístico-discursivos performativizados são os da "feminilidade", pois, segundo a lógica daqueles contextos históricos de dominação masculina, coube à mulher os cuidados da esfera privada, ou seja, da esfera doméstica, dado um processo de individualização da casa em relação aos espaços públicos, por exemplo, da rua. Em outros termos, para as mulheres foram impostas atividades ligadas ao cotidiano da casa e da família. Assim, Dilma reitera os sentidos de uma "ordem masculina", e configura um ethos de "identificação", pois reproduz tal estrutura de dominação;

(6) As mulheres são também aliadas do desenvolvimento sustentável e de uma necessária mudança de padrões de consumo. Conto com vocês para promover expressiva participação feminina na Conferência das Nações Unidas sobre Desenvolvimento Sustentável - a Rio+20, que o Brasil terá o privilégio de sediar em $2016[\ldots]$.

Dilma performativiza sentidos linguístico-discursivos da "feminilidade", pois no imaginário popular a ideia de consumo está ligada à imagem feminina, ou seja, são as mulheres que consomem mais, são as mulheres que estão mais próximas dos detalhes da rotina de uma casa, dos filhos, do esposo, etc. Em suma, temos na seguinte passagem de seu discurso a iterabilidade de um estereótipo. No entanto, a "feminilidade" se constitui juntamente com a "feminilitude", pois o sentido que configura a imagem de si do feminino é o de "mobilização", pois, no mesmo ato que, implicitamente, reconhece que as mulheres são consumidoras potenciais, também as mobiliza para ressignificarem politicamente a historicidade de tal estereótipo, ou seja, para participarem de decisões para além da esfera da vida privada. Dilma configura um ethos que denominamos por "agenciamento";

(7) As mulheres são especialmente interessadas na construção de um mundo mais pacífico e seguro. Quem gera a vida não aceita a violência como meio de solução de conflitos. Por isso devemos nos engajar na reforma da governança global para que a comunidade internacional tenha mecanismos mais representativos e eficazes 
de ação como a paz sustentável. A existência de conflitos armados vitima, especialmente, as mulheres e - cada vez mais - as crianças $[\ldots]$.

Aqui, o objetivo Dilma é a busca pela paz. Para tanto, isso ocorre por meio de um engajamento político das próprias mulheres. Em outros termos, Rousseff convoca as mulheres a se engajarem nas lutas e demandas referentes aos conflitos armados, pois o seu pressuposto é o de que as mulheres sabem muito melhor do que os homens sobre a importância que tem uma "vida”, pois são elas que geram "vidas" e perpetuam descendências. Em outros termos, Rousseff lança mão da prerrogativa da maternidade. Os sentidos linguístico-discursivos da "feminilidade" são mobilizados por Dilma, servindo de apoio para o argumento de que as mulheres precisam se engajar nos problemas globais, para que mudanças/rupturas com velhas mentalidades, ou melhor, com velhos padrões produzidos em contextos de dominação masculina, possam ser ressignificados. Emerge a partir dessa reivindicação uma mulher agente, que articula o seu poder para que tantas outras possam ser inseridas nas esferas públicas e políticas, ou seja, nas esferas de poder. A nosso ver, o seu discurso é provocador. Assim sendo, tais características configuram um ethos de "contestação";

(8) Além disso, as mulheres estão sujeitas à violência em tempos de paz, muitas vezes sofridas em suas próprias casas. Para combater esse mal, o Brasil criou delegacias especializadas e uma central de atendimento à mulher, bem como estabeleceu legislação especial de prevenção e punição das agressões feitas às mulheres, denominada Lei Maria da Penha, reconhecida hoje em todo o mundo. Tenho certeza de que uma mudança cultural também seja necessária para por fim ao lamentável, mas persistente hábito, de atribuir às mulheres a responsabilidade pela violência que sofrem $[\cdots]$.

$\mathrm{Na}$ passagem acima, Dilma performativiza os sentidos linguísticodiscursivos da "feminilitude", pois, claramente, ela não compactua com a violência doméstica e não atribui a culpa à mulher pelos companheiros violentos que dividem com elas a vida. Rousseff não só reconhece os 
mecanismos jurídicos disponíveis de combate a essa violência, muitas vezes silenciosa, mas também clarifica que a questão da violência é cultural, portanto, histórica. A força histórica da dominação masculina, das relações desiguais entre os gêneros, da lógica perversa que coloca as mulheres numa posição de objeto é contestada, pois ela aponta para a existência de estereótipos culturais, embora implícitos em seu discurso. Observamos a configuração de um ethos de "contestação";

(9) A recusa da desigualdade é plenamente compatível com a valorização da diferença. Promover os direitos humanos é combater a discriminação baseada em gênero, raça, condição física, orientação sexual, pensamentos diferentes e religião. Essas lutas são todas indissociáveis. Sei que nos momentos difíceis cada uma de nós busca força e inspiração nas mulheres que ao longo da história resistiram a todas as formas de opressão. Naquelas que apareceram diante do mundo e também em todas as mulheres anônimas e suas lutas anônimas. A elas agradeço a possibilidade de ocupar esta tribuna e de dizer a todas as meninas e mulheres do mundo que com coragem, tenacidade e altivez, é possível conquistar os nossos sonhos $[\ldots]$.

O sentido linguístico-discursivo configurador da imagem do feminino no discurso de Dilma é de solidariedade para com todos aqueles que se consolidaram e ainda se consolidam como objetos de uma visão masculina/falocrática, dependendo da civilização/da sociedade em que se encontram. Em sociedades as quais predomina ou predominou a referida visão, os homens são os sujeitos da "História" e também de suas próprias "histórias". Estão excluídos desse grupo dominante, mesmo que de modo implícito, os homossexuais, os negros, os pobres e, claro, as mulheres e as crianças, ou seja, todos aqueles que se encontram na periferia dos centros hegemônicos de dominação, que impõe sua força por meio de processos discursivos e sociais que naturalizam os sentidos dessa dominação. Com um discurso firme e encorajador, Rousseff mobiliza seu poder e ressignifica sentidos históricos tais como o de "coragem" "tenacidade" e "altivez" que foram naturalizados como características exclusivas do universo masculino, que agora, em seu discurso, também podem ser performativizados pelas 
mulheres, pois ela mesma estiliza os sentidos linguageiros da "coragem".

: Essas características constituem sentidos da "feminilitude" e configuram um ethos de "empoderamento", pois Dilma deixa bem claro o poder que detém, pelo lugar público e político que ocupava.

\section{CONSIDERAÇÕES FINAIS}

Norteada por uma perspectiva pragmático-discursiva, a presente pesquisa se apoiou-se em teorias que refutam todo e qualquer essencialismo, ou seja, os pressupostos de toda uma tradição filosófica ocidental que, ao longo dos tempos, rebaixou a linguagem a uma função reveladora de significações elaboradas fora das relações sociais, dos contextos sociais, da história. Vale ressaltar que a ideia de que o sujeito seria detentor de um logos, lugar onde ocorreria a produção da significação, sustentou a função designativa da linguagem. Contudo, tal status da linguagem foi refutado, pelos argumentos austinianos, em que a linguagem é uma "forma de ação". Dessa forma, apoiando-se em tal ideia, Judith Butler, ao contestar o argumento de que o sujeito, consequentemente, a identidade de gênero teria um status ontológico, radicalizou o "ato performativo" austiniano e propôs a noção de "performatividade de gênero", performatividade que consiste num processo de estilização de gênero, em detrimento de noções naturalizantes de gênero no interior de uma matriz denominada pela autora por "heteronormativa".

Assim, o tema da identidade foi mobilizado pela ideia de "performatividade", mais especificamente, as categorias analíticas ethos, "feminilidade" e "feminilitude", com vistas à reprodução, à resistência e à ressignificação de traços de sentidos que poderiam estar apontando para a reiteração de estereótipos históricos constituidores da identidade de gênero. Em suma, os resultados obtidos foram que a identidade de Dilma tanto é de "legitimação" de sentidos de uma "ordem social masculina", quanto de resistência frente a tal ordem, pois dependendo do contexto, mobiliza o seu poder político para promover agenciamentos que visem a mudanças, inclusive estruturais, que favoreçam as mulheres. Mas, muito mais do que isso, no discurso analisado, observamos que Rousseff também estiliza uma identidade de projeto, pois articula o seu poder para promover tais mudanças em favor do aumento cada vez mais de mulheres nos espaços de 
poder como, por exemplo, nos ministérios do seu governo.

O corpo não é matéria inerte, apto a receber significações, ou seja, não consiste num lugar para que ocorram inscrições culturais. A imagem do feminino no discurso de Dilma Rousseff, ou seja, a imagem de sua identidade feminina se constituiu pelo uso que a mesma fez e ainda faz da sua linguagem, de modo situado, junto ao movimento de seu corpo, enquanto agente identitário do feminino.

\section{REFERÊNCIAS BIBLIOGRÁFICAS}

AMOSSY, Ruth (org.). Imagens de si no discurso: a construção do ethos. 1. ed., $1^{a}$ reimpressão. São Paulo: Contexto, 2008.

ARISTÓTELES. Retórica. Tradução Manuel Alexandre Júnior, Paulo Farmhouse Alberto e Abel do Nascimento Pena. $2^{\mathrm{a}}$ ed. Lisboa: Biblioteca de Autores Clássicos, 2005.

AUSTIN, John L. Quando dizer é fazer: palavras e ação. Tradução Danilo Marcondes de Souza Filho. Porto Alegre: Artes médicas, 1990.

BHABHA, Homi K. A outra questão: o estereótipo, a discriminação e o discurso colonial. In: __. O local da cultura. Tradução de Myriam Ávila, Eliana Lourenço de Lima, Glaucia Renata Gonçalves. $5^{\text {a }}$ reimpressão. Belo Horizonte: Ed. UFMG, 2010.

BOURDIEU, Pierre. A dominação masculina. Tradução Maria Helena Kuhner. $8^{a}$ ed. Rio de Janeiro: Bertrand Brasil, 2010.

BUTLER, Judith. Gender Trouble: Feminism and the subversion of identity. New York: Routledge, 1990.

. Problemas de gênero: feminismo e subversão da identidade. Tradução Renato Aguiar. $3^{a}$.ed. Rio de Janeiro: Civilização Brasileira, 2010.

CASTELLS, Manuel. O poder da identidade. Tradução Klauss Brandini Gerhardt. São Paulo: Editora Paz e Terra Ltda., 2010. 
DERRIDA, Jacques. Assinatura, acontecimento, contexto. In:

: As margens da filosofia. Tradução Joaquim Torres Costa, Antônio M. Magalhães; Revisão técnica Constança Marcondes Cesar. Campinas, SP: Papirus, 1991.

FIORIN, José Luiz. Enunciação e comunicação. In: FIGARO, Roseli (orga.). Comunicação e Análise do Discurso. São Paulo: Contexto, 2012.

MAINGUENEAU, Dominique. Discurso literário. Tradução Adail Sobral.São Paulo: Contexto, 2006.

. A propósito do ethos. In: MOTTA, Ana Raquel; SALGADO, Luciana (orgs). Ethos discursivo. São Paulo: Contexto, 2008.

MARTINS FERREIRA, Dina Maria. Discurso feminino e identidade social. $2^{\text {a }}$. ed. São Paulo: Annablume; Fapesp, 2009.

. Identidade feminina no espaço político: percurso simbólico na ecologia da linguagem. In: RAJAGOPALAN, Kanavillil; MARTINS FERREIRA, Dina. Políticas em linguagem: perspectivas identitárias. São Paulo: Editora Mackenzie, 2006.

PINTO, Joana Plaza. Estilizações de gênero em discurso sobre linguagem. Tese (Doutorado em Linguística). Instituto de Estudos da Linguagem. Universidade Estadual de Campinas, Campinas, SP, 2002.

SILVA, Tomaz T. A produção social da identidade e da diferença. In: (org.). Identidade e diferença: a perspectiva dos estudos culturais. 8. ed. Petrópolis, RJ: Vozes, 2008. 